\title{
Long-term survival effect of the interval between mastectomy and radiotherapy in locally advanced breast cancer
}

\author{
Wen-Wen Zhang',* \\ San-Gang $\mathbf{W u}^{2}, *$ \\ Jia-Yuan Sun' \\ Feng-Yan $\mathrm{Li}^{\prime}$ \\ Zhen-Yu He'
}

'Department of Radiation Oncology, Sun Yat-sen University Cancer Center, State Key Laboratory of Oncology in South China, Collaborative Innovation Center of Cancer Medicine, Guangzhou 510060, People's Republic of China; ${ }^{2}$ Department of Radiation Oncology, Xiamen Cancer Hospital, The First Affiliated Hospital of Xiamen University, Xiamen 361003, People's Republic of China

*These authors contributed equally to this work
This article was published in the following Dove Press journal: Cancer Management and Research

\begin{abstract}
Introduction: The timing of postmastectomy radiotherapy (PMRT) may influence locoregional recurrence and survival outcomes. In this study, we assessed the long-term survival effect of the interval between surgery and PMRT in locally advanced breast cancer treated with mastectomy and adjuvant chemotherapy.
\end{abstract}

Methods: In this retrospective study, we included women with locally advanced breast cancer who underwent adjuvant chemotherapy and PMRT after mastectomy between 1999 and 2007. Based on the interval between surgery and PMRT, the patients were classified into three groups: Group 1 ( $\leq 4$ vs $>4$ months), Group 2 ( $\leq 5$ vs $>5$ months), and Group 3 ( $\leq 6$ vs $>6$ months). Univariate and multivariate regression analyses were performed to determine the prognostic factors of survival outcomes.

Results: A total of 340 women were included in this study, and the median follow-up duration was 79.8 months. The median surgery-PMRT interval was 5 months. The surgery-PMRT interval including Group 1, Group 2, and Group 3 was not significantly associated with locoregional recurrence-free survival, distant metastasis-free survival, disease-free survival, and overall survival. In addition, in the subgroup analysis of the effect of surgery-PMRT interval on survival outcomes according to various clinicopathologic factors, the surgery-PMRT interval was also not associated with survival outcomes in different age groups, tumor stage, and breast cancer subtypes.

Conclusion: Our findings suggest that the delay in the start of PMRT in locally advanced breast cancer does not increase the likelihood of locoregional recurrence, distant metastasis, and death. Keywords: breast carcinoma, surgery, time, irradiation, delay

\section{Introduction}

Patients with locally advanced breast cancer, which is defined as stage III disease, had a higher risk for locoregional recurrence (LRR). Approximately $30 \%$ of patients with high-risk breast cancer develop LRR after mastectomy, but the administration of postmastectomy radiotherapy (PMRT) may reduce LRR and improve survival outcomes. ${ }^{1-3}$ In these high-risk patients, the interval between PMRT administration and mastectomy may affect LRR and survival outcomes. However, the optimal time between surgery and PMRT remains unclear.

There are conflicting results regarding the optimal interval between surgery and radiotherapy. However, it has been reported that an interval $>6-12$ weeks in patients not receiving chemotherapy, and an interval >6-7 months in patients receiving adjuvant chemotherapy after surgery, may lead to a higher risk of recurrence. ${ }^{4-9}$
Correspondence: Zhen-Yu He Yat-Sen University Cancer Center, Stat Key Laboratory of Oncology in South China, Collaborative Innovation Center of Cancer Medicine, 65I Dongfeng Road East, Guangzhou 510060, People's Republic of China

Tel +862087343543

Fax +86 2087343392

Email hezhy@sysucc.org.cn 
Several retrospective studies have yielded variable findings in women receiving breast-conserving surgery. ${ }^{5,10-14}$ Adjuvant chemotherapy and radiotherapy is the standard treatment for high-risk breast cancer after mastectomy. ${ }^{15} \mathrm{In}$ this study, we retrospectively assessed the long-term survival effect of the surgery-PMRT interval in women with locally advanced breast cancer treated with mastectomy and adjuvant chemotherapy.

\section{Materials and methods}

\section{Patients}

We retrospectively analyzed the medical data of patients with breast cancer who underwent mastectomy between 1999 and 2009 at the Sun Yat-Sen University Cancer Center, Guangzhou, China. Patients were eligible for inclusion in this study if:

- in accordance with the current tumor $(\mathrm{T})$ node $(\mathrm{N})$ metastasis (M) staging system, they had stage III breast cancer;

- they underwent mastectomy, and at least 4 cycles adjuvant chemotherapy followed by PMRT;

- PMRT was administrated to the chest wall and supraclavicular lymph nodes to a prescription dose of $50 \mathrm{~Gy}$ in 25 fractions; and

- they had complete clinicopathologic and follow-up data.

All patients gave their written informed consent to use of their medical records, and the clinical ethics committee of the Sun Yat-sen University Cancer Center approved this study.

\section{Clinicopathologic factors}

The following clinicopathologic factors were included: age; menopausal status; tumor stage; hormone receptor (HoR) status; and human epidermal growth factor receptor-2 (HER2) status. The expressions of estrogen receptor (ER), progesterone receptor (PR), and HER2 were assessed in accordance with our previous study. ${ }^{16} \mathrm{ER}$ and PR positivity were defined as immunohistochemistry findings of $>1 \%$ positive cells. HER 2 positivity was defined as an immunohistochemistry score of $3+$ or $2+$ with confirmation by fluorescence in situ hybridization. The breast cancer subtypes (BCS) were classified as four subtypes according to HoR and HER2 status: HoR+/HER2-, HoR+/HER2+, HoR-/HER2+, and HoR-/HER2 - subtypes. Based on the interval between mastectomy and radiotherapy, the patients were classified into three groups: Group 1 ( $\leq 4$ vs $>4$ months), Group 2 ( $\leq 5$ vs $>5$ months), and Group 3 ( $\leq 6$ vs $>6$ months). The primary endpoints of this study were locoregional recurrence-free survival (LRFS), distant metastasis-free survival (DMFS), disease-free survival (DFS), and overall survival (OS). LRR was defined as pathologically confirmed recurrence including ipsilateral chest wall, axillary lymph nodes, supraclavicular and subclavian lymph nodes, or internal mammary lymph nodes. Distant metastasis was defined as tumor recurrence at a site distal to the primary cancer. DFS referred to absence of LRR or distant metastasis. OS was defined as the time from initial diagnosis to the date of death or last follow-up.

\section{Statistical analysis}

The $\chi^{2}$-test or Fisher's exact test was performed to compare differences between the three interval groups. The survival curves were estimated using the Kaplan-Meier method and compared using the log-rank test. Univariate and multivariate Cox regression analyses were performed to investigate the risk factors for survival outcomes. In the univariate analysis, the survival differences were investigated according to age, menopausal status, tumor stage, BCS, and timing of PMRT administration. Multivariate Cox regression analyses were then performed to identify the independent predictors from those statistically significant in the univariate analysis. Statistical analyses were performed using SPSS (version 21.0; IBM Corporation, Armonk, NY, USA). A $P$ value $<0.05$ was considered statistically significant.

\section{Results}

A total of 340 patients were included in this study. The characteristics of the patients are presented in Table 1. Their median age was 45 years (range, 24-74 years), and 65.3\% were premenopausal. There were 168 (49.4\%), 14 (4.1\%), and $158(46.5 \%)$ patients with IIIA, IIIB, and IIIC stage disease, respectively. There were $52.1 \%, 21.2 \%, 14.1 \%$, and $12.6 \%$ of patients with HoR+/HER2-, HoR+/HER2+, HoR-/HER2+, and HoR-/HER2 - subtypes, respectively.

All patients underwent mastectomy, axillary lymph node dissection, adjuvant chemotherapy, and PMRT. Most of the patients (98.2\%) received anthracycline-and-taxane-based chemotherapy, and the median of chemotherapy courses was 6 (range, 4-12). Patients with HoR-positive disease received endocrine therapy, and only two patients with HER2-positive disease were treated with trastuzumab-containing regimens. All patients received PMRT to the chest wall and supraclavicular lymph nodes. The internal mammary lymph nodes were not routinely irradiated.

The median surgery-PMRT interval was 5 months (range, 3-15 months). Patient characteristics by surgery-PMRT interval are listed in Table 1. In Group 1 ( $n=78$ in $\leq 4$ months, $\mathrm{n}=262$ in $>4$ months), there were no significant differences 
Table I Baseline characteristics according to interval category $(n=340)$

\begin{tabular}{|c|c|c|c|c|c|c|c|c|c|c|}
\hline \multirow[t]{2}{*}{ Characteristic } & \multirow[t]{2}{*}{$\mathbf{n}$} & \multicolumn{3}{|l|}{ Group I } & \multicolumn{3}{|l|}{ Group 2} & \multicolumn{3}{|l|}{ Group 3} \\
\hline & & $\begin{array}{l}\leq 4 \text { months } \\
(n=78)(\%)\end{array}$ & $\begin{array}{l}>4 \text { months } \\
(n=262)(\%)\end{array}$ & $P$ & $\begin{array}{l}\leq 5 \text { months } \\
(n=204)(\%)\end{array}$ & $\begin{array}{l}>5 \text { months } \\
(n=136)(\%)\end{array}$ & $P$ & $\begin{array}{l}\leq 6 \text { months } \\
(n=285)(\%)\end{array}$ & $\begin{array}{l}>6 \text { months } \\
(n=55)(\%)\end{array}$ & $P$ \\
\hline \multicolumn{11}{|l|}{ Age (years) } \\
\hline$<35$ & 43 & II (I4.I) & $32(12.2)$ & 0.372 & $33(16.2)$ & $10(7.4)$ & 0.032 & $37(13.0)$ & $6(10.9)$ & 0.716 \\
\hline $35-49$ & 178 & $45(57.7)$ & $133(50.8)$ & & $107(52.5)$ & $7 \mid(52.2)$ & & $|5|(53.0)$ & $27(49.1)$ & \\
\hline$\geq 50$ & 119 & $22(28.2)$ & $97(37.0)$ & & $64(31.4)$ & $55(40.4)$ & & $97(34.0)$ & $22(40.0)$ & \\
\hline \multicolumn{11}{|l|}{ Menopausal status } \\
\hline Premenopausal & 222 & $54(69.2)$ & $168(64.1)$ & 0.420 & |4| (69.1) & $81(59.6)$ & 0.081 & $189(66.3)$ & $33(60.0)$ & 0.439 \\
\hline Postmenopausal & 118 & $24(30.8)$ & $94(35.9)$ & & $63(30.9)$ & $55(40.4)$ & & $96(33.7)$ & $22(40.0)$ & \\
\hline \multicolumn{11}{|l|}{ Tumor stage } \\
\hline IIIA & 168 & $36(46.2)$ & $132(50.4)$ & 0.768 & $103(50.5)$ & $65(47.8)$ & $0.54 I$ & $143(50.2)$ & $25(45.5)$ & 0.868 \\
\hline IIIB & 14 & $3(3.8)$ & II (4.2) & & $10(4.9)$ & $4(2.9)$ & & $12(4.2)$ & $2(3.6)$ & \\
\hline IIIC & 158 & $39(50.0)$ & $119(45.4)$ & & 91 (44.6) & $67(49.3)$ & & $130(45.6)$ & $28(50.9)$ & \\
\hline \multicolumn{11}{|c|}{ Breast cancer subtype } \\
\hline HoR+/HER2- & 177 & $41(52.6)$ & $136(5 \mid .9)$ & 0.392 & $104(5 \mid .0)$ & $73(53.7)$ & 0.397 & | 48 (5 I.9) & $29(52.7)$ & 0.930 \\
\hline HoR+/HER2+ & 72 & $17(21.8)$ & $55(21.0)$ & & $48(23.5)$ & $24(17.6)$ & & $61(21.4)$ & II (20.0) & \\
\hline HoR-/HER2+ & 48 & $14(17.9)$ & $34(13.0)$ & & $30(14.7)$ & $18(13.2)$ & & $39(13.7)$ & $9(16.4)$ & \\
\hline HoR-/HER2- & 43 & $6(7.7)$ & $37(14.1)$ & & $22(10.8)$ & $21(15.4)$ & & $37(13.0)$ & $6(10.9)$ & \\
\hline \multicolumn{11}{|c|}{ Chemotherapy regime } \\
\hline CMF & 6 & $3(3.8)$ & $3(1.1)$ & 0.136 & $4(2.0)$ & $2(1.5)$ & 1.000 & 5 & $\mathrm{I}(\mathrm{I} .8)$ & 1.000 \\
\hline $\begin{array}{l}\text { Anthracycline/ } \\
\text { taxane regimens }\end{array}$ & 334 & $75(96.2)$ & $259(98.9)$ & & $200(98.0)$ & $134(98.5)$ & & 280 & $54(98.2)$ & \\
\hline \multicolumn{11}{|c|}{ Chemotherapy courses } \\
\hline $4-6$ & 277 & 70 (89.7) & $209(79.8)$ & 0.063 & I83 (89.7) & $96(70.6)$ & $<0.001$ & $242(84.9)$ & $37(67.3)$ & 0.003 \\
\hline$>6$ & 61 & $8(10.3)$ & $53(20.2)$ & & $21(10.3)$ & $40(29.4)$ & & $43(15.1)$ & $18(32.7)$ & \\
\hline
\end{tabular}

Abbreviations: CMF, cyclophosphamide, epirubicin/adriamycin, fluorouracil; HER2, human epidermal growth factor receptor-2; HoR, hormone receptor.

in patient characteristics between the two cohorts. In Group 2 ( $\mathrm{n}=204$ in $\leq 5$ months, $\mathrm{n}=136$ in $>5$ months), patients with a surgery-PMRT interval $>5$ months were more likely to be aged $\geq 50$ years and receive $>6$ cycles of chemotherapy. In addition, in Group 3 ( $n=285$ in $\leq 6$ months, $n=55$ in $>6$ months), patients with a surgery-PMRT interval $>6$ months were more likely to receive $>6$ cycles of chemotherapy.

The median follow-up time was 79.8 months (range, 5-166 months). A total of 36 patients developed LRR, and the 10 -year LRFS was $86.3 \%$. The details on event distribution of LRR and distant metastasis are listed in Table 2. The 10-year DMFS, DFS, and OS were $60.6 \%, 51.5 \%$, and $61.1 \%$, respectively.

Table 3 shows the univariate analyses of survival outcomes. The surgery-PMRT interval including Group 1, Group 2, and Group 3 was not significantly associated with LRFS, DMFS, DFS, or OS. In addition, in the subgroup analysis of the effect of surgery-PMRT interval on survival outcomes according to various clinicopathologic factors, the surgery-PMRT interval was also not associated with survival outcomes in different age groups, tumor stage, and BCS. The survival curves in Group 1, Group 2, and Group 3 are shown in Figures 1-3, respectively. The BCS was the independent significant predictor for LRFS, menopausal status, tumor stage, and BCS were the independent significant predictors for DMFS and DFS, while age, tumor stage, and BCS were the independent significant predictors for OS.

\section{Discussion}

In this study, we assessed the long-term survival effect of the interval between surgery and PMRT in women with locally advanced breast cancer. Our results showed that the delay in the start of PMRT in locally advanced breast cancer is not related to an increased risk of LRR, distant recurrence, or death.

Reportedly, $\sim 50 \%$ of patients experience delayed postoperative radiotherapy. ${ }^{17}$ For ethical reasons, it is impossible to conduct a randomized controlled trial to assess the effect of the surgery-radiotherapy interval on survival outcomes in patients with breast cancer. Hence, the optimal surgeryradiotherapy interval remains unclear. Theoretically, the risk of LRR or distant recurrence is related to the residual tumor burden in the surgical bed. Therefore, a long interval before PMRT after breast surgery may increase the likelihood of 
Table 2 The details on event distribution between groups

\begin{tabular}{|c|c|c|c|c|c|c|}
\hline \multirow[t]{2}{*}{ Recurrence site } & \multicolumn{2}{|l|}{ Group I } & \multicolumn{2}{|l|}{ Group 2} & \multicolumn{2}{|l|}{ Group 3} \\
\hline & $\begin{array}{l}\leq 4 \text { months } \\
(n=78)(\%)\end{array}$ & $\begin{array}{l}>4 \text { months } \\
(n=262)(\%)\end{array}$ & $\begin{array}{l}\leq 5 \text { months } \\
(n=204)(\%)\end{array}$ & $\begin{array}{l}>5 \text { months } \\
(n=136)(\%)\end{array}$ & $\begin{array}{l}\leq 6 \text { months } \\
(n=285)(\%)\end{array}$ & $\begin{array}{l}>6 \text { months } \\
(n=55)(\%)\end{array}$ \\
\hline \multicolumn{7}{|l|}{ LRR (single site) } \\
\hline Chest wall & $\mathrm{I}(\mathrm{I} .3)$ & $12(4.6)$ & $8(3.9)$ & $5(3.7)$ & $9(3.2)$ & $4(7.3)$ \\
\hline Supra-/infraclavicular lymph node & $3(3.8)$ & $6(2.3)$ & $5(2.5)$ & $4(2.9)$ & $9(3.2)$ & $0(0)$ \\
\hline Internal mammary lymph node & $0(0)$ & $0(0)$ & $0(0)$ & $0(0)$ & $0(0)$ & $0(0)$ \\
\hline Axillary lymph node & $2(2.5)$ & $2(0.7)$ & $3(1.5)$ & $\mathrm{I}(0.7)$ & $3(1.1)$ & $\mathrm{I}(\mathrm{I} .8)$ \\
\hline LRR ( $\geq 2$ LRR sites) & $3(3.8)$ & $7(2.7)$ & $8(3.9)$ & $2(1.5)$ & $10(3.5)$ & $0(0)$ \\
\hline Distant metastasis & $27(34.6)$ & $89(34.0)$ & $75(36.8)$ & $4 I(30.1)$ & $100(35.1)$ & $16(29.1)$ \\
\hline
\end{tabular}

Abbreviation: LRR, locoregional recurrence.

Table 3 Univariate Cox regression analysis of prognostic factors

\begin{tabular}{|c|c|c|c|c|c|c|c|c|}
\hline \multirow[t]{2}{*}{ Characteristic } & \multicolumn{2}{|l|}{ LRFS } & \multicolumn{2}{|l|}{ DMFS } & \multicolumn{2}{|l|}{ DFS } & \multicolumn{2}{|l|}{ OS } \\
\hline & HR (95\% Cl) & $P$ & HR (95\% Cl) & $P$ & HR (95\% Cl) & $P$ & HR (95\% Cl) & $P$ \\
\hline \multicolumn{9}{|l|}{ Age (years) } \\
\hline$<35$ & I & & I & & 1 & & 1 & \\
\hline $35-49$ & $0.553(0.197-1.55 I)$ & 0.260 & $0.77 \mid(0.427-\mid .392)$ & 0.388 & $0.628(0.384-1.027)$ & 0.064 & $0.467(0.268-0.814)$ & 0.007 \\
\hline$\geq 50$ & $\mathrm{I} .277(0.474-3.44 \mathrm{I})$ & 0.629 & $1.303(0.720-2.358)$ & 0.381 & $1.004(0.610-1.654)$ & 0.987 & $0.890(0.515-1.538)$ & 0.677 \\
\hline \multicolumn{9}{|l|}{ Menopausal status } \\
\hline Premenopausal & 1 & & 1 & & I & & I & \\
\hline Postmenopausal & $1.798(0.934-3.46 \mathrm{I})$ & 0.079 & $1.519(1.050-2.196)$ & 0.026 & $1.429(1.026-1.989)$ & 0.035 & $1.416(1.017-1.972)$ & 0.040 \\
\hline \multicolumn{9}{|l|}{ Tumor stage } \\
\hline IIIA & $\mathrm{I}$ & & I & & 1 & & 1 & \\
\hline IIIB & $0.968(0.127-7.379)$ & 0.975 & $1.682(0.665-4.258)$ & 0.272 & $1.382(0.52 \mathrm{I}-3.465)$ & 0.490 & $1.635(0.651-4.110)$ & 0.296 \\
\hline IIIC & $1.878(0.954-3.697)$ & 0.068 & $2.171(1.478-3.189)$ & $<0.001$ & $2.308(1.639-3.252)$ & $<0.001$ & $2.365(1.675-3.340)$ & $<0.001$ \\
\hline \multicolumn{9}{|c|}{ Breast cancer subtype } \\
\hline HR+/HER2- & I & & I & & 1 & & 1 & \\
\hline HR+/HER2+ & $1.522(0.599-3.867)$ & 0.378 & $1.265(0.763-2.096)$ & 0.362 & $1.086(0.69 I-1.708)$ & 0.720 & $0.999(0.635-1.570)$ & 0.995 \\
\hline HR-/HER2+ & $2.835(1.157-6.94 I)$ & 0.023 & $2.349(1.438-3.836)$ & 0.001 & $2.004(1.290-3.114)$ & 0.002 & $1.634(1.048-2.547)$ & 0.030 \\
\hline HR-/HER2- & 3.773 (1.586-8.977) & 0.003 & $2.330(1.405-3.864)$ & 0.001 & $1.833(1.150-2.923)$ & 0.011 & $1.882(1.180-3.001)$ & 0.008 \\
\hline \multicolumn{9}{|l|}{ Treatment interval } \\
\hline$\leq 4$ months & 1 & & 1 & I & I & & I & \\
\hline$>4$ months & $0.885(0.416-1.884)$ & 0.752 & $1.00 I(0.650-|.54|)$ & 0.998 & $0.954(0.654-1.393)$ & 0.808 & $0.966(0.630-1.575)$ & 0.988 \\
\hline \multicolumn{9}{|l|}{ Treatment interval } \\
\hline$\leq 5$ months & 1 & & 1 & & I & & 1 & \\
\hline$>5$ months & $0.725(0.362-1.452)$ & 0.365 & $0.769(0.525-1.126)$ & 0.177 & $0.905(0.648-1.265)$ & 0.559 & $0.918(0.618-1.365)$ & 0.674 \\
\hline \multicolumn{9}{|l|}{ Treatment interval } \\
\hline$\leq 6$ months & $\mathrm{I}$ & & I & & I & & 1 & \\
\hline$>6$ months & $0.804(0.3 \mid 3-2.069)$ & 0.651 & $0.765(0.451-1.296)$ & 0.319 & $0.789(0.492-1.266)$ & 0.327 & $0.688(0.385-|.23|)$ & 0.208 \\
\hline
\end{tabular}

Abbreviations: DFS, disease-free survival; DMFS, distant metastasis-free survival; HER2, human epidermal growth factor receptor-2; HoR, hormone receptor; HR, hazard ratio; LRFS, locoregional recurrence-free survival; OS, overall survival.

residual tumor growth and the development of radioresistance, consequently leading to a poorer outcome. ${ }^{18,19}$

Controversy continues to surround the surgery-radiotherapy interval in patients with breast cancer who receive breast-conserving surgery. In the International Breast Cancer Study Group trials, the timing of radiotherapy after breastconserving surgery was not significantly associated with the LRFS, DFS, and OS of patients who received initial chemotherapy or endocrine therapy. ${ }^{10,11}$ Two populationbased cohort studies also found that starting radiotherapy shortly after breast-conserving surgery did not improve the long-term survival outcomes of patients with or without chemotherapy. ${ }^{13,14}$ However, a meta-analysis indicated that delayed radiotherapy after breast-conserving surgery was associated with a significantly higher risk of LRR. ${ }^{12}$ In addition, a population-based study of the Surveillance Epidemiology and End Results Program that included 18,050 women with stage $0-$ II disease after breast-conserving surgery and radiotherapy (but not chemotherapy) showed that an interval $>6$ weeks was associated with an increased likelihood 
A
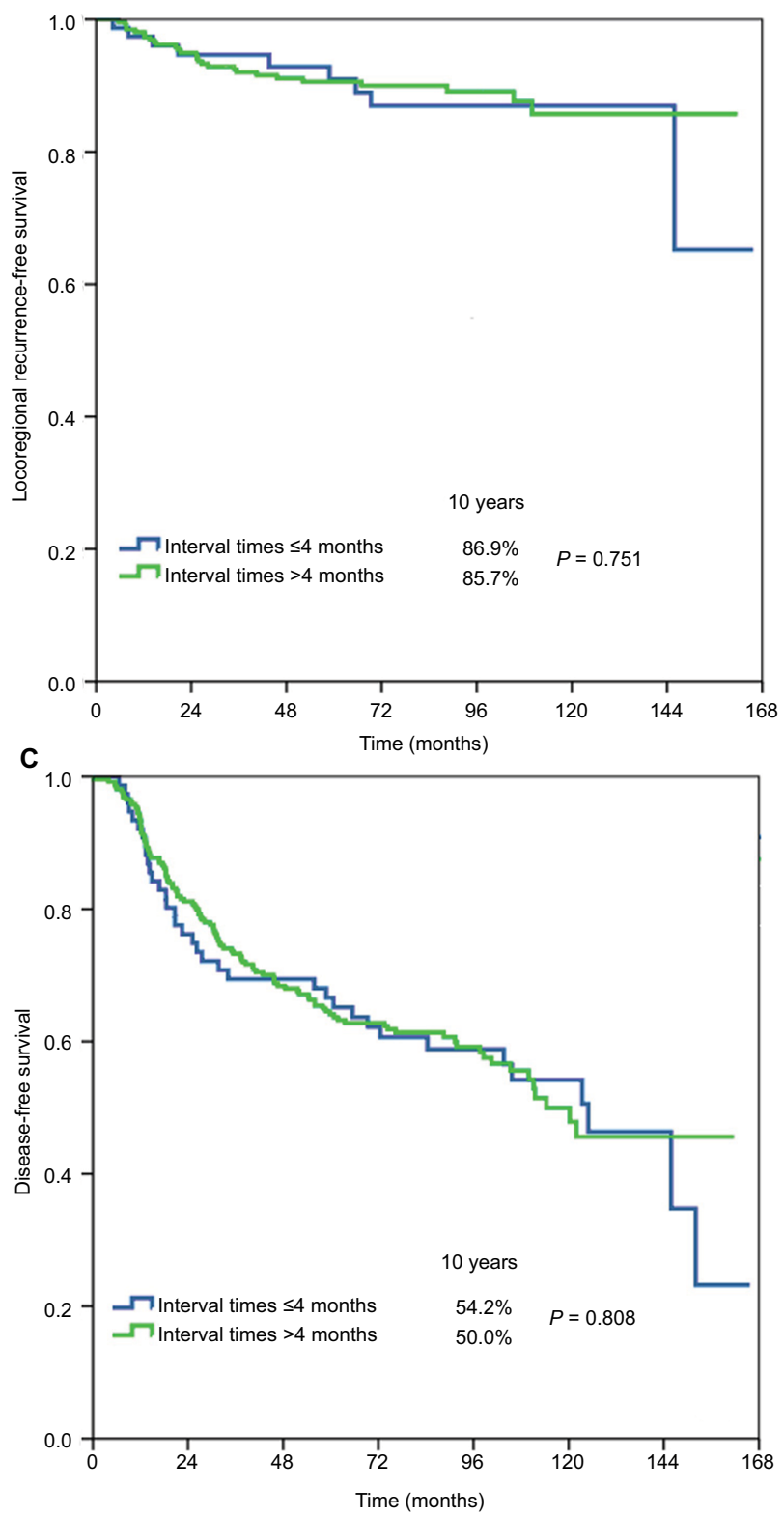

B
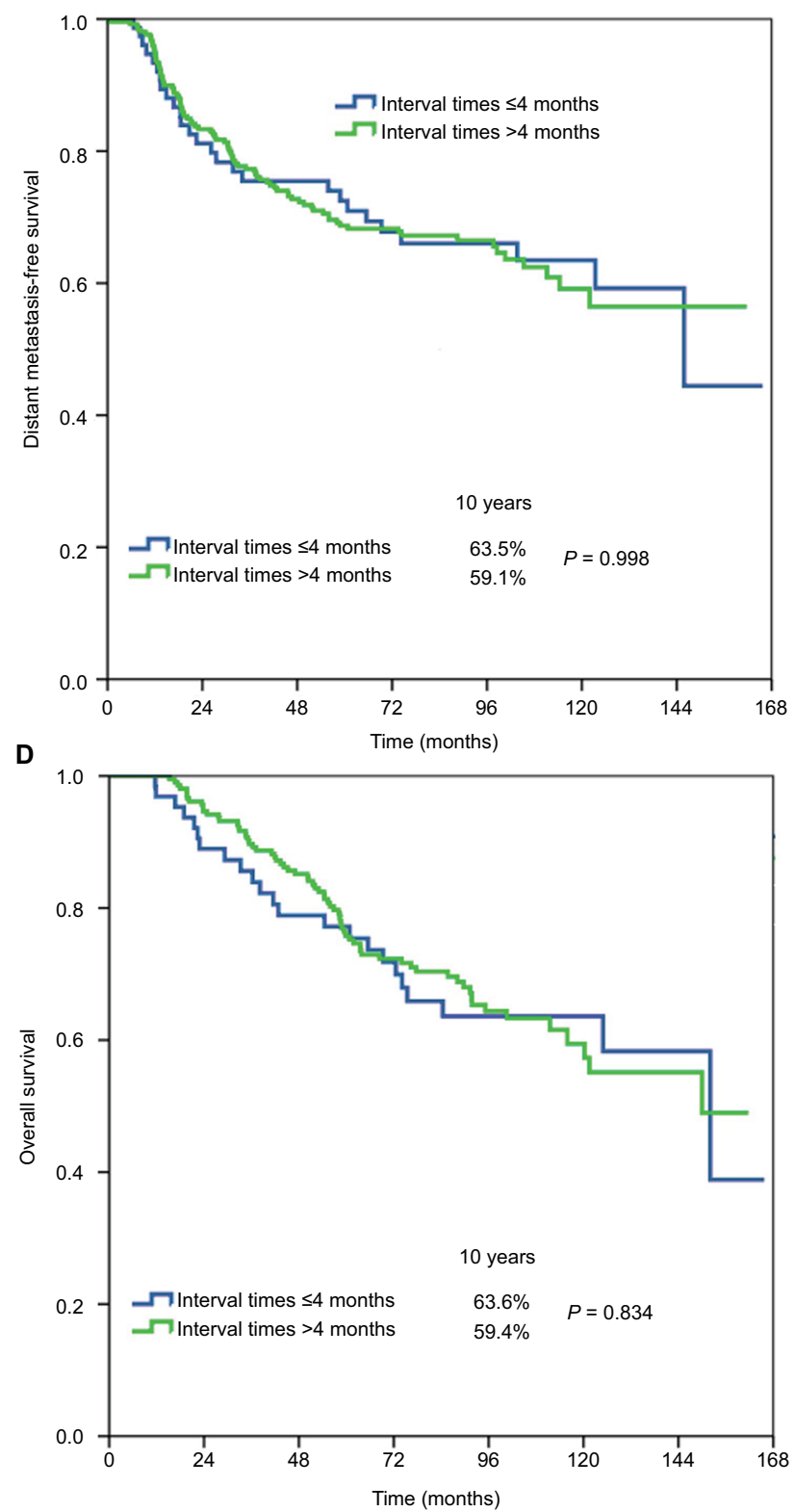

Figure I Locoregional recurrence-free survival (A), distant metastasis-free survival (B), disease-free survival (C), and overall survival (D) in Group I ( $\leq 4$ vs $>4$ months).

of LRR. ${ }^{5}$ These results suggest that radiotherapy should be initiated as soon as possible after breast-conserving surgery in patients not receiving chemotherapy.

Approximately $30 \%$ of locally advanced breast cancer may develop LRR after mastectomy, but the administration of PMRT may reduce LRR and decrease the incidence of systemic relapse. ${ }^{1-3}$ The optimal interval between mastectomy and PMRT in patients with locally advanced disease remains unclear. However, several retrospective studies have shown that the interval between mastectomy and PMRT in patients with locally advanced breast cancer is not associated with survival outcomes. Kim et $\mathrm{al}^{20}$ after examining
275 patients with stage I-IIIB disease treated with chemotherapy and PMRT found that delaying the start of PMRT ( $\leq 2$ vs $>2$ months and $\leq 6$ vs $>6$ months) did not affect LRR or survival outcomes. Metz et $\mathrm{al}^{21}$ assessed 221 patients with locally advanced breast cancer who received mastectomy and showed that delayed PMRT did not adversely affect LRR at 8 years. The rates of LRR at 8 years were $13 \%, 4 \%$, and $12 \%$ in patients with surgery-PMRT intervals of $\leq 2,2.1-6$, and $>6$ months, respectively $(P=0.51) .{ }^{21}$ Desai et al ${ }^{22}$ examined 248 patients and demonstrated no significant effect of the surgery-PMRT interval on LRR in patients who underwent neoadjuvant chemotherapy and mastectomy. 

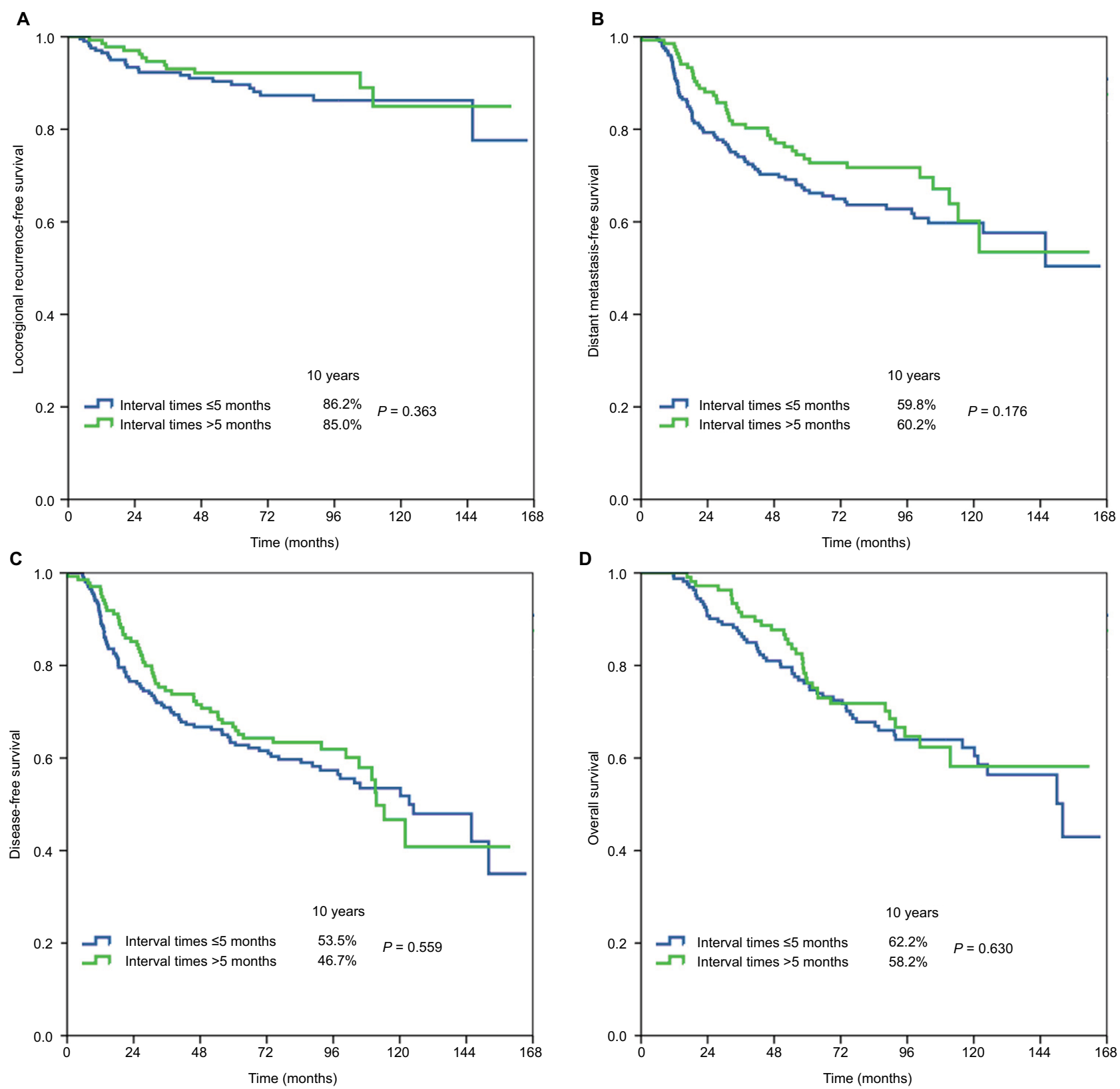

Figure 2 Locoregional recurrence-free survival (A), distant metastasis-free survival (B), disease-free survival (C), and overall survival (D) in Group 2 ( $\leq 5$ vs $>5$ months).

The participants of this study were classified based on the interval between surgery and the initiation of PMRT. Our findings indicated that the survival benefit of PMRT is maintained up to 6 months. Our findings were similar to those of the aforementioned studies. ${ }^{20-22}$ That is, the survival outcomes and patterns of treatment failure did not differ according to the interval between mastectomy and PMRT. The German Society for Radiooncology recommends that PMRT should be started 4-6 weeks after surgery or completion of the primary or adjuvant chemotherapy. ${ }^{23}$ Although the optimal interval between mastectomy and
PMRT cannot be determined from the available evidence, patient anxiety is related to the waiting time for PMRT; thus, we propose that patients start PMRT as soon as possible after mastectomy.

Delayed administration of PMRT can result from various social and patient factors, including a lack of adequate equipment and personnel, treatment at cancer centers, a desire for breast reconstruction, and the problem of wound healing, which lead to long waiting lists. ${ }^{24}$ Although timely access to PMRT remains a priority for all centers, the clinical efficacy of PMRT is maintained even when the start of PMRT 
A

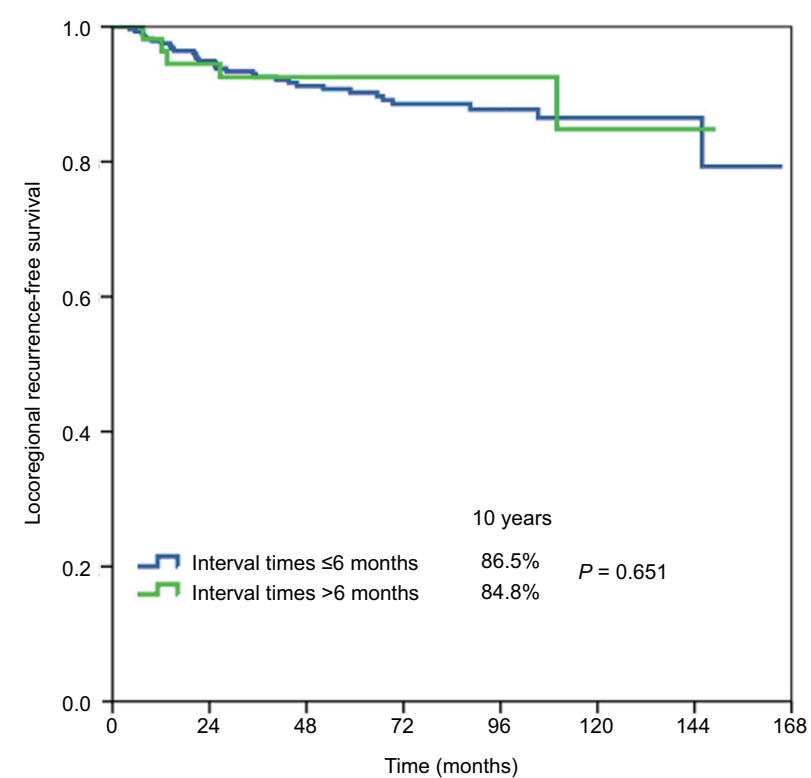

C

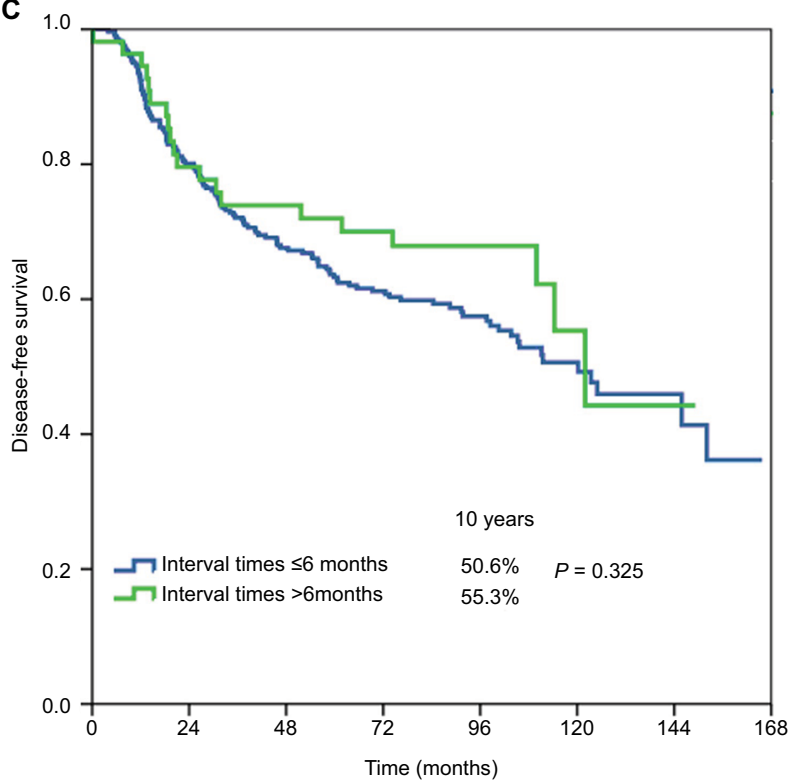

B

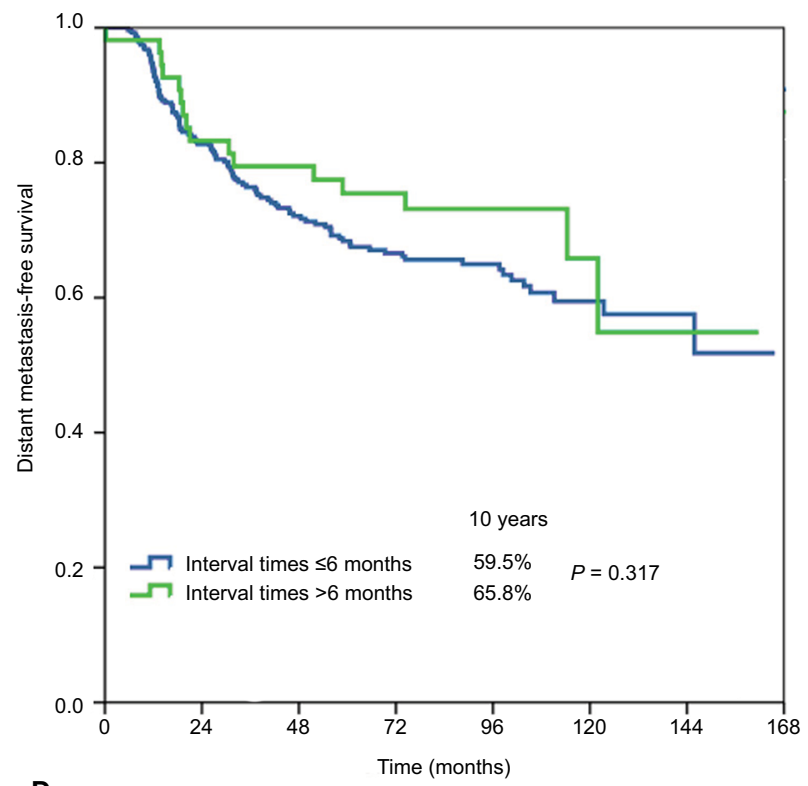

D

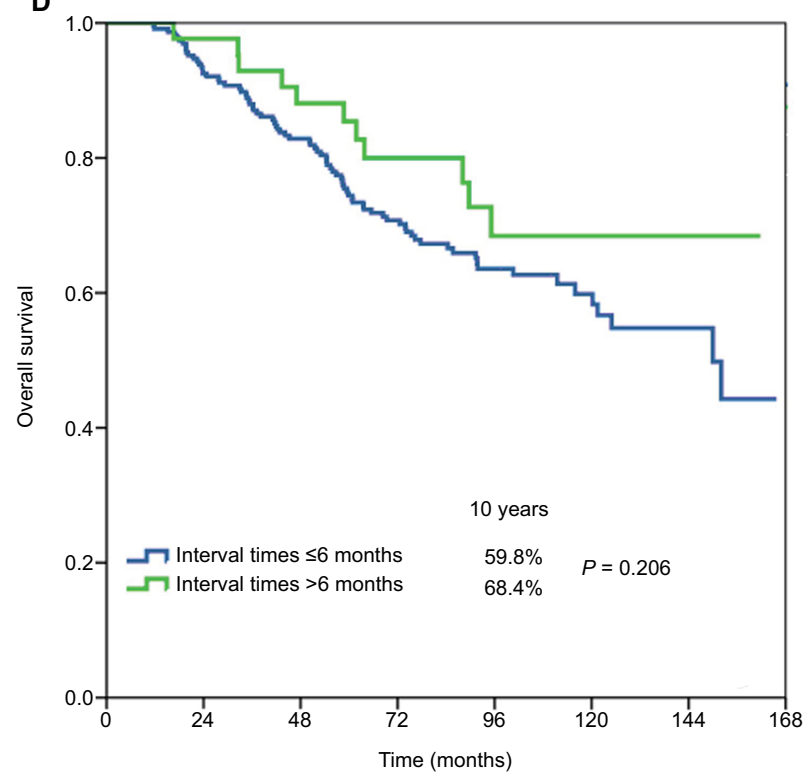

Figure 3 Locoregional recurrence-free survival (A), distant metastasis-free survival (B), disease-free survival (C), and overall survival (D) in Group 3 ( $\leq 6$ vs $>6$ months).

is delayed. PMRT should still be administered to patients who have experienced a delay but have not developed LRR. ${ }^{22}$

The primary limitation of our study is its retrospective nature from a single institution; however, the effect of the surgery-radiotherapy interval on survival is a subject ethically inappropriate for randomized studies. Therefore, retrospective studies are a reasonable choice to confirm the impact of the surgery-radiotherapy interval on breast cancer recurrence. In addition, this study was limited by its small sample size and limited follow-up time. Moreover, most of the patients with HER2-positive disease did not receive trastuzumab-based treatment, which was the standard of care in the modern series; therefore, the results of this study are less applicable to the general population of breast cancer patients.

\section{Conclusion}

In conclusion, our results suggest that the delay in the start of PMRT in locally advanced breast cancer does not increase the likelihood of LRR, distant metastasis, and death.

\section{Acknowledgments}

This work was partly supported by the Natural Science Foundation of Fujian Province (No. 2016J01635), and the Science 
and Technology Planning Projects of Xiamen Science \& Technology Bureau (No. 3502Z20174070), and Guangdong Medical Research Foundation (No. A2017023). The authenticity of this article has been validated by uploading the key raw data onto the Research Data Deposit (RDD) public platform (www. researchdata.org.cn), with the approval RDD number as RDDA2018000693.

\section{Disclosure}

The authors report no conflicts of interest in this work.

\section{References}

1. EBCTCG (Early Breast Cancer Trialists' Collaborative Group), McGale $\mathrm{P}$, Taylor $\mathrm{C}$, et al. Effect of radiotherapy after mastectomy and axillary surgery on 10-year recurrence and 20-year breast cancer mortality: meta-analysis of individual patient data for 8135 women in 22 randomised trials. Lancet. 2014;383(9935):2127-2135.

2. Overgaard M, Hansen PS, Overgaard J, et al. Postoperative radiotherapy in high-risk premenopausal women with breast cancer who receive adjuvant chemotherapy. Danish Breast Cancer Cooperative Group 82b Trial. N Engl J Med. 1997;337(14):949-955.

3. Ragaz J, Jackson SM, Le N, et al. Adjuvant radiotherapy and chemotherapy in node-positive premenopausal women with breast cancer. N Engl J Med. 1997;337(14):956-962.

4. Nixon AJ, Recht A, Neuberg D, et al. The relation between the surgeryradiotherapy interval and treatment outcome in patients treated with breast-conserving surgery and radiation therapy without systemic therapy. Int J Radiat Oncol Biol Phys. 1994;30(1):17-21.

5. Punglia RS, Saito AM, Neville BA, Earle CC, Weeks JC. Impact of interval from breast conserving surgery to radiotherapy on local recurrence in older women with breast cancer: retrospective cohort analysis. BMJ. 2010;340:c845.

6. Tsoutsou PG, Koukourakis MI, Azria D, Belkacémi Y. Optimal timing for adjuvant radiation therapy in breast cancer: a comprehensive review and perspectives. Crit Rev Oncol Hematol. 2009;71(2):102-116.

7. Vujovic O, Cherian A, Yu E, Dar AR, Stitt L, Perera F. The effect of timing of radiotherapy after breast-conserving surgery in patients with positive or close resection margins, young age, and node-negative disease, with long term follow-up. Int J Radiat Oncol Biol Phys. 2006;66(3):687-690.

8. Whelan TJ, Julian J, Wright J, Jadad AR, Levine ML. Does locoregional radiation therapy improve survival in breast cancer? A meta-analysis. J Clin Oncol. 2000;18(6):1220-1229.

9. Huang J, Barbera L, Brouwers M, Browman G, Mackillop WJ.Does delay in starting treatment affect the outcomes of radiotherapy? A systematic review. J Clin Oncol. 2003;21(3):555-563.
10. Karlsson P, Cole BF, Colleoni M, et al. Timing of radiotherapy and outcome in patients receiving adjuvant endocrine therapy. Int $J$ Radiat Oncol Biol Phys. 2011;80(2):398-402.

11. Karlsson P, Cole BF, Price KN, et al. Timing of radiation therapy and chemotherapy after breast-conserving surgery for node-positive breast cancer: long-term results from international breast cancer study group trials VI and VII. Int J Radiat Oncol Biol Phys. 2016;96(2): 273-279.

12. Gupta S, King WD, Korzeniowski M, Wallace DL, Mackillop WJ. The effect of waiting times for postoperative radiotherapy on outcomes for women receiving partial mastectomy for breast cancer: a systematic review and meta-analysis. Clin Oncol (R Coll Radiol). 2016;28(12):739-749.

13. van Maaren MC, Bretveld RW, Jobsen JJ, et al. The influence of timing of radiation therapy following breast-conserving surgery on 10-year disease-free survival. Br J Cancer. 2017;117(2):179-188.

14. Corradini S, Niemoeller OM, Niyazi M, et al. Timing of radiotherapy following breast-conserving surgery: outcome of 1393 patients at a single institution. Strahlenther Onkol. 2014;190(4):352-357.

15. National Comprehensive Cancer Network, Breast cancer. Version 2. 2017, Available from: https://www.nccn.org/professionals/physician_gls/pdf/breast.pdf. Accessed September 2, 2017.

16. Wu SG, Sun JY, Zhou J, et al. Number of negative lymph nodes can predict survival of breast cancer patients with four or more positive lymph nodes after postmastectomy radiotherapy. Radiat Oncol. 2014;9:284.

17. Benk VM, Levinton C, Fortin PR, et al. 2055 Effect of delay in initiating radiotherapy for patients with early stage breast cancer: results of a natural experiment. Int J Radiat Oncol Biol Phys.1999,45(3): 305-306.

18. Mackillop WJ, Bates JH, O'Sullivan B, Withers HR. The effect of delay in treatment on local control by radiotherapy. Int J Radiat Oncol Biol Phys. 1996;34(1):243-250.

19. Fletcher GH. Implications of the density of clonogenic infestation in radiotherapy. Int J Radiat Oncol Biol Phys. 1986;12(9):1675-1680.

20. Kim HJ, Kim JS, Chie EK, Noh DY, Bang YJ, Ha SW. The sequencing of chemotherapy and radiotherapy in breast cancer patients after mastectomy. Tumori. 2010;96(1):28-33.

21. Metz JM, Schultz DJ, Fox K, Mathews A, Glick J, Solin LJ. Analysis of outcomes for high-risk breast cancer based on interval from surgery to postmastectomy radiation therapy. Cancer J. 2000;6(5):324-330.

22. Desai S, Hurley J, Takita C, et al. Impact of surgery-radiation interval on locoregional outcome in patients receiving neo-adjuvant therapy and mastectomy. Breast J. 2013;19(4):427-430.

23. Sautter-Bihl ML, Souchon R, Budach W, et al. DEGRO practical guidelines for radiotherapy of breast cancer II. Postmastectomy radiotherapy, irradiation of regional lymphatics, and treatment of locally advanced disease. Strahlenther Onkol. 2008;184(7):347-353.

24. Belkacémi Y, Fourquet A, Cutuli B, et al; Expert Review Board of Nice/Saint-Paul de Vence. Radiotherapy for invasive breast cancer: guidelines for clinical practice from the French expert review board of Nice/Saint-Paul de Vence. Crit Rev Oncol Hematol. 2011;79(2):91-102.
Cancer Management and Research

Publish your work in this journal

Cancer Management and Research is an international, peer-reviewed open access journal focusing on cancer research and the optimal use of preventative and integrated treatment interventions to achieve improved outcomes, enhanced survival and quality of life for the cancer patient. The manuscript management system is completely online and includes a very quick and fair peer-review system, which is all easy to use. Visit http://www.dovepress.com/testimonials.php to read real quotes from published authors. 